\title{
Otomatisasi Transaksi Toko Online Berbasis Woocommerce Menggunakan Bot Telegram
}

\author{
Syaifudin Zuhri*1, Gita Indah Marthasari², Yufis Azhar ${ }^{3}$ \\ 1,2,3Teknik Informatika/Universitas Muhammadiyah Malang \\ szuhri1@gmail.com¹, gita@umm.ac.id², yufis@umm.ac.id ${ }^{3}$
}

\begin{abstract}
Abstrak
Penelitian ini mengusulkan satu solusi untuk memaksimalkan pelayanan toko online berbasis Woocommerce dengan otomatisasi. Layanan otomatisasi ini berfungsi untuk pencarian informasi mengenai katalog produk dan pembantu dalam proses pembelian produk toko online. Aplikasi dibangun dengan memanfaatkan Bot Telegram yang ada pada Telegram Messenger. Bot Telegram dipilih karena memiliki dokumentasi Bot API yang cukup lengkap dan semakin berkembang. Bot Telegram dirancang dengan menggunakan bahasa pemrograman PHP dengan memanfaatkan framework Laravel. Metode yang digunakan untuk pembuatan Bot Telegram adalah metode Webhook. Pengambilan informasi katalog dan proses pembelian produk memanfaatkan API Woocommerce yang di integrasikan dengan Bot Telegram. Informasi diperoleh dengan memberikan perintah tertentu kepada Bot Telegram. Beberapa perintah dibuat dengan memanfaatkan fungsi keyboard yang telah disediakan oleh Bot Telegram. Pengujian dilakukan dengan mencoba tombol yang telah disediakan pada menu dan berjalan dengan baik.
\end{abstract}

Kata Kunci: Bot Telegram, Woocommerce, Transaksi Online, PHP

\section{Abstract}

This study proposes a solution to maximize Woocommerce-based online shop services with automation. This automation service serves to search for information about product catalogs and helpers in the process of purchasing online store products. The application was built using the Telegram Bot on Telegram Messenger. Telegram Bot was chosen because they have a complete and increasingly developed Bot API documentation. Telegram Bot is designed using the PHP programming language by utilizing the Laravel framework. The method used for making Telegram Bot is Webhook method. Retrieving catalog information and product purchasing processes using Woocommerce API that integrated with the Telegram Bot. Information is obtained by giving certain commands to the Telegram Bot. Some commands are made using keyboard functions that have been provided by the Telegram Bot. Testing is done by trying buttons provided on menu and running well.

Keywords: Telegram Bot, Woocommerce, Online Transaction, PHP

\section{Pendahuluan}

Toko online dan transaksi online di Indonesia terus mengalami peningkatan yang pesat dalam waktu 5 tahun terakhir. Di dapatkan data dari eMarketer, pada tahun 2014, transaksi online mencapai nilai Rp25,1 triliun dan pada tahun 2018, nilai transaksi online diperkirakan akan terus naik sampai Rp144,1 triliun [1]. Dengan meningkatnya transaksi online, dibutuhkan pelayanan yang lebih baik. Dampak lain yang dihasilkan adalah bertambahnya kebutuhan tenaga kerja. Dari permasalahan ini, bisa dilakukan otomatisasi dalam pelayanan yang dapat mengurangi kebutuhan tenaga kerja. Zafrada merupakan toko online yang berbasis Woocommerce. Woocommerce sendiri merupakan plugin penjualan yang disediakan Wordpress. Selain berjalan diatas Wordpress, Woocommerce juga menyediakan REST API sehingga bisa diintegrasikan dengan sistem lain.

Tren masyarakat saat ini lebih cenderung melakukan interaksi via instant messenger daripada via web. Instant messenger telah digunakan sebagai sarana untuk berkomunikasi yang merupakan salah satu aktivitas manusia [2]. Ini bisa dilihat dari data eMarketer yang menunjukkan pengguna instant messenger di Indonesia pada tahun 2014 sebanyak 36,7 juta pengguna dan meningkat pada tahun 2017 mencapai 72,5 juta pengguna [3]. Dengan semakin bertambahnya pengguna instant messenger, terbuka peluang baru untuk pemasaran produk menggunakan 
gabungan web dan instant messenger. Penggunaan instant messenger memiliki kelemahan yang sangat mendasar, yaitu membutuhkan SDM untuk menerima ataupun menjawab pesan yang masuk melalui instant messenger. Dengan kata lain, kebutuhan tenaga kerja semakin bertambah. Hal ini dapat diatasi dengan penggunaan bot untuk menerima dan menjawab pesan yang masuk. Bot sendiri memiliki arti program komputer yang bisa melakukan pekerjaan tertentu secara otomatis [4].

Saat ini belum terdapat bot yang mendukung integrasi dengan Woocommerce. Sistem dari instant messenger yang mendukung penggunaan bot juga belum banyak, contohnya ada Line, Facebook Messenger, dan Telegram. Aplikasi yang gratis, ringan dan multiplatform adalah alasan digunakannya Bot Telegram [5]. Bot API yang dimiliki Telegram juga cukup lengkap dan semakin berkembang, sehingga memungkinkan untuk pembuatan bot pintar yang dapat merespon pesan dari penggunanya [6].

Bot Telegram memang memiliki kegunaan yang sangat banyak. Sebagai contoh bot untuk membantu pekerjaan dan aktivitas harian, sebagai hiburan dan sosial media, membantu menemukan serta mengumpulkan informasi[7]. Dari penelitian sebelumnya yang di jadikan sebagai referensi, Bot Telegram digunakan sebagai alat kuesioner evaluasi belajar [8] dan pemberian layanan informasi tertentu [9].

Dari keterangan diatas, ingin dikembangkan sebuah website toko online yang terintegrasi dengan bot telegram sebagai layanan pendukung. Fungsi Bot Telegram adalah untuk menampilkan katalog yang ada pada website toko online. Telegram bot juga dapat membantu dalam proses pembelian tanpa harus membuka halaman web. Dengan dibuatnya sistem ini, diharapkan dapat membantu dalam mencari informasi katalog produk dan proses transaksi pembelian.

\section{Metode Penelitian}

Pada penelitian ini, Bot Telegram nantinya dapat menampilkan informasi berupa katalog produk di Telegram Messenger yang digunakan. Informasi katalog produk diambil dari toko online berbasis Woocommerce menggunakan API yang telah disediakan. Pengguna dapat melihat katalog dengan beberapa perintah yang tersedia, seperti perintah melihat produk terbaru, terpopuler, dan termurah. Bot Telegram juga dapat membantu pengguna pada saat melakukan proses pembelian produk. Proses pembelian produk melalui Bot Telegram selesai sampai pengguna melakukan checkout. Bot Telegram akan dibangun dengan menggunakan bahasa pemrograman PHP (PHP: Hypertext Preprocessor) dan memanfaatkan framework Laravel. Metode yang digunakan dalam membangun Bot Telegram adalah metode Webhook [10]. Metode ini dipilih karena membuat Bot Telegram diletakkan dalam sebuah server online dan dapat diakses terus menerus.

Arsitektur sistem Bot Telegram dapat dilihat pada Gambar 1. User yang dalam penelitian ini adalah pembeli memberikan pesan atau perintah kepada Bot Telegram melalui Aplikasi Telegram. Pesan kemudian diterima oleh Server Telegram dan diteruskan pada Server Bot. Server Bot akan mengolah pesan tersebut, mengambil data dari toko online bila diperlukan dan memberikan respon yang tepat kepada pembeli. Respon akan dikirim pada Aplikasi Telegram pembeli melalui Server Telegram. Setelah respon diberikan pembeli dapat memberikan pesan baru pada Bot Telegram atau mengakhiri interaksi.

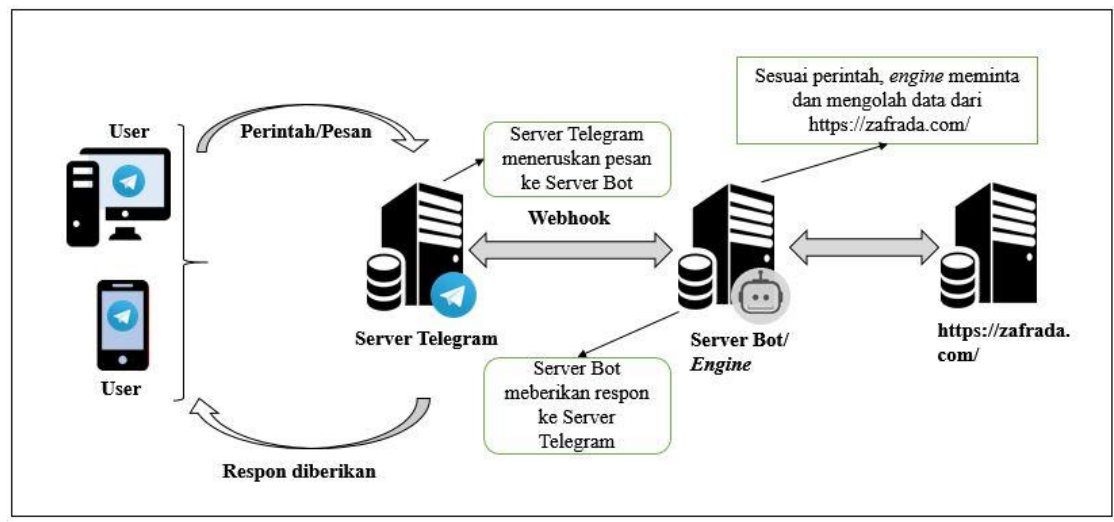

Gambar 1. Arsitektur Bot Telegram

REPOSITOR, Vol. 2, No. 6, Juni 2020: 717-726 
Pada Server Bot, ada proses yang dilakukan oleh Bot Telegram sebelum memberikan respon kepada pembeli. Proses itu adalah identifikasi kategori perintah yang dapat diberikan oleh pembeli. Perintah yang disediakan pada penelitian ini secara umum adalah perintah untuk melihat katalog dan perintah pembelian barang. Diagram alur proses dapat dilihat pada Gambar 2.

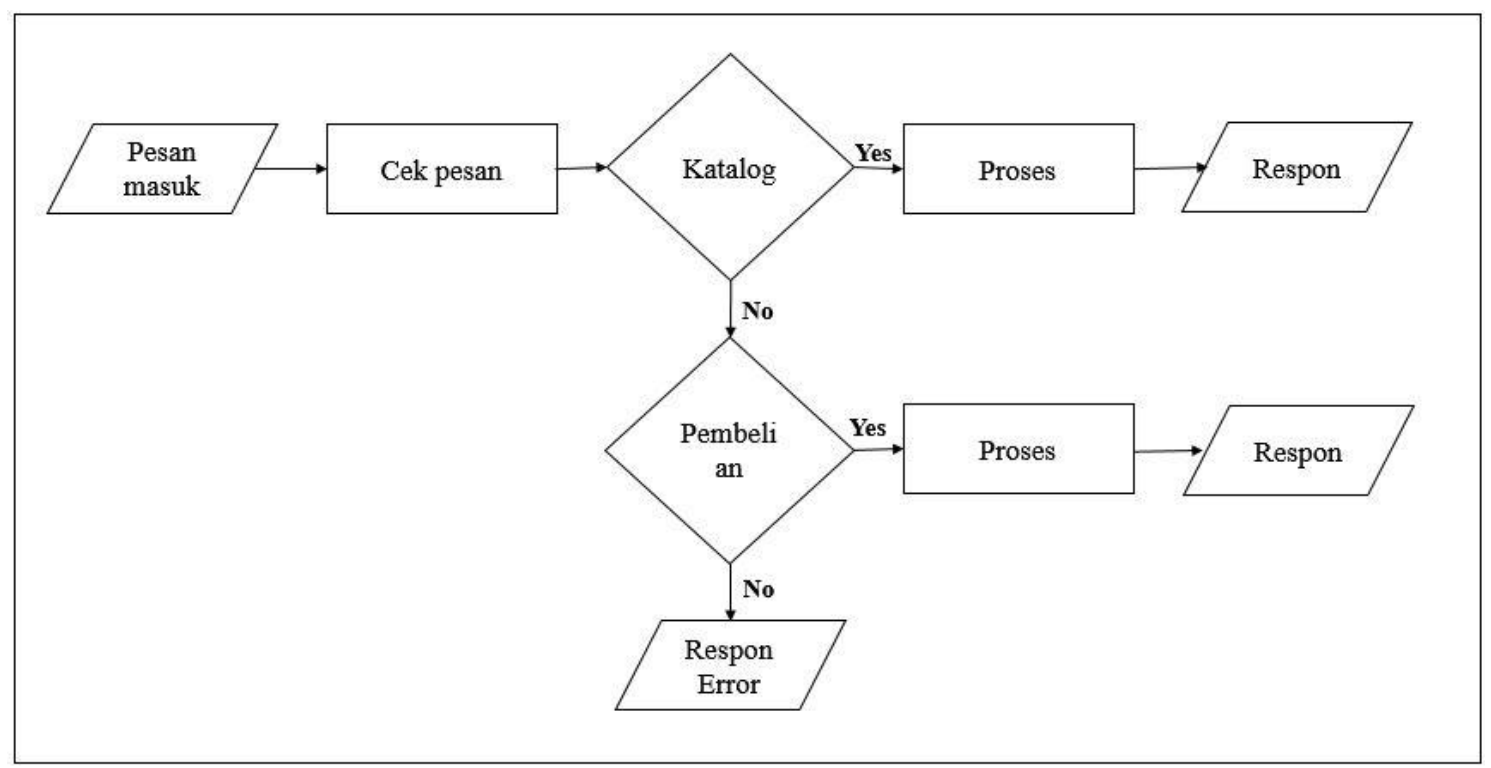

Gambar 2. Proses pada Bot Telegram Secara Umum

Untuk memudahkan pembeli dalam memberikan perintah pada Bot Telegram dan untuk mengurangi kesalahan pengetikan, beberapa perintah dibuat dalam bentuk tombol. Sedangkan untuk perintah yang tidak bisa menggunakan tombol, pembeli harus tetap memasukkan keyword sesuai dengan kebutuhan. Beberapa perintah yang disediakan pada penelitian ini dapat dilihat pada Tabel 1 berikut.

Tabel 1. Jenis perintah yang disediakan

\begin{tabular}{ccc}
\hline Tampilan & Perintah & $\begin{array}{c}\text { Penggunaan } \\
\text { Tombol }\end{array}$ \\
\hline Tampilan Utama & Katalog & Menggunakan \\
Tampilan Cari Produk & Cari Produk & Menggunakan \\
Tampilan Katalog & Inputan kata & Tidak \\
& Terbaru & Menggunakan \\
& Terpopuler & Menggunakan \\
& Termurah & Menggunakan \\
& Termahal & Menggunakan \\
Tampilan Kategori & Kategori & Menggunakan \\
& Nama Kategori & Menggunakan \\
& Halaman Selanjutnya & Menggunakan \\
& Halaman Sebelumnya & Menggunakan \\
Tampilan Produk & Kembali & Menggunakan \\
& Beli Barang & Menggunakan \\
& Halaman Selanjutnya & Menggunakan \\
& Halaman Sebelumnya & Menggunakan \\
& Kembali & Menggunakan \\
Tampilan Beli Barang & Variasi Produk & Menggunakan \\
& Jumlah Produk & Tidak \\
& Inputan Data Pembeli & Tidak \\
& Lanjutkan Pembelian & Menggunakan \\
& Batalkan pembelian & Menggunakan \\
\hline
\end{tabular}




\subsection{Sequence Diagram Cek Katalog}

Sequence Diagram Cek Katalog menggambarkan bagaimana pembeli melakukan proses melihat katalog yang ada. Pembeli memasukkan perintah atau pesan melalui aplikasi Telegram. Perintah kemudian diteruskan oleh Server Telegram kepada Bot Telegram. Bot Telegram akan melakukan pengecekan perintah dan selanjutnya meminta data pada Woocommerce. Setelah mendapatkan data dari Woocommerce, data akan dioleh dan selanjutnya data akan ditampilkan pada layar pengguna. Sequence Diagram Cek Katalog dapat dilihat pada Gambar 3.

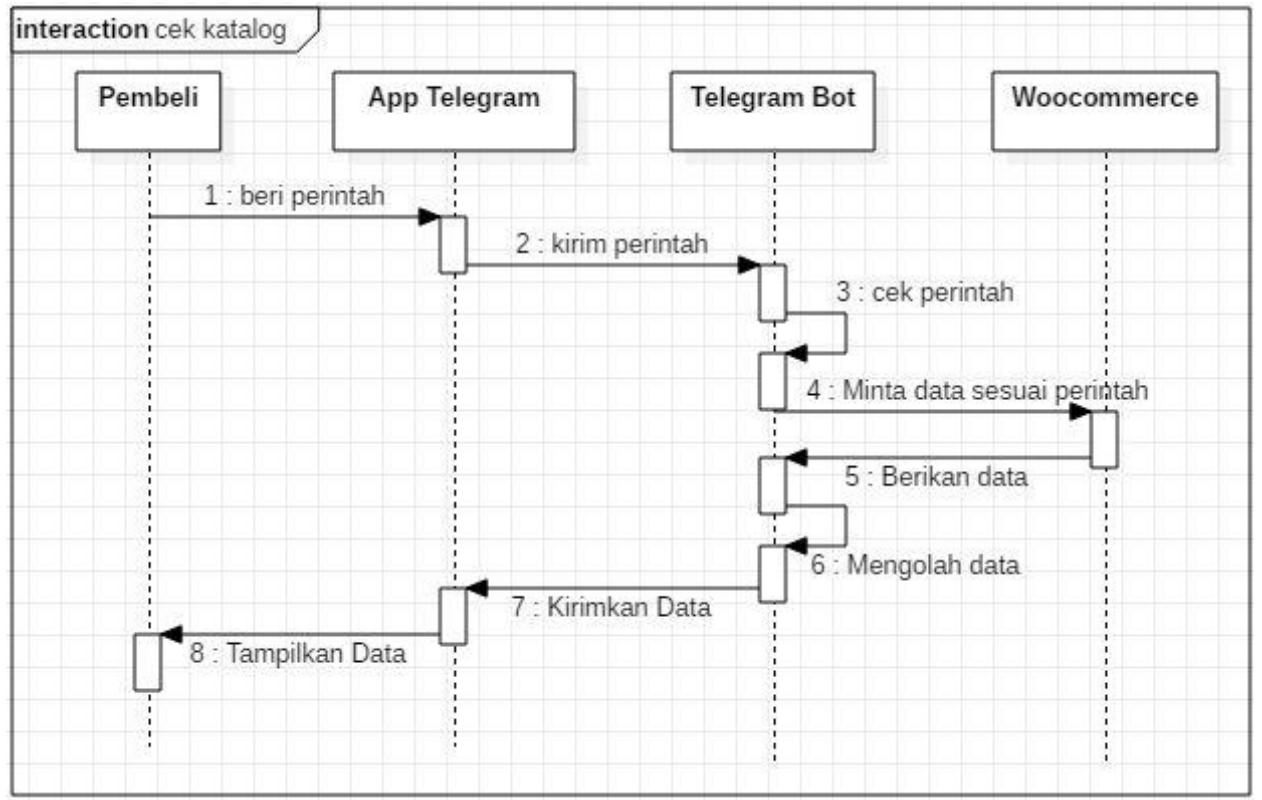

Gambar 3. Sequence Diagram Cek Katalog

\subsection{Sequence Diagram Pembelian}

Sequence Diagram Pembelian menggambarkan bagaimana pembeli melakukan proses pembelian barang. Pembeli akan melakukan perintah beli barang. Perintah kemudian disampaikan pada Bot Telegram. Selanjutnya Bot Telegram memberi respon pada pembeli untuk memasukkan data pembelian. Setelah data pembelian dimasukkan, data diproses oleh Bot Telegram dan dikirimkan pada Woocommerce. Setelah pengiriman sukses, Bot Telegram akan memberikan respon pada pembeli bahwa pembelian sukses dilakukan. Sequence Diagram Pembelian dapat dilihat pada Gambar 4.

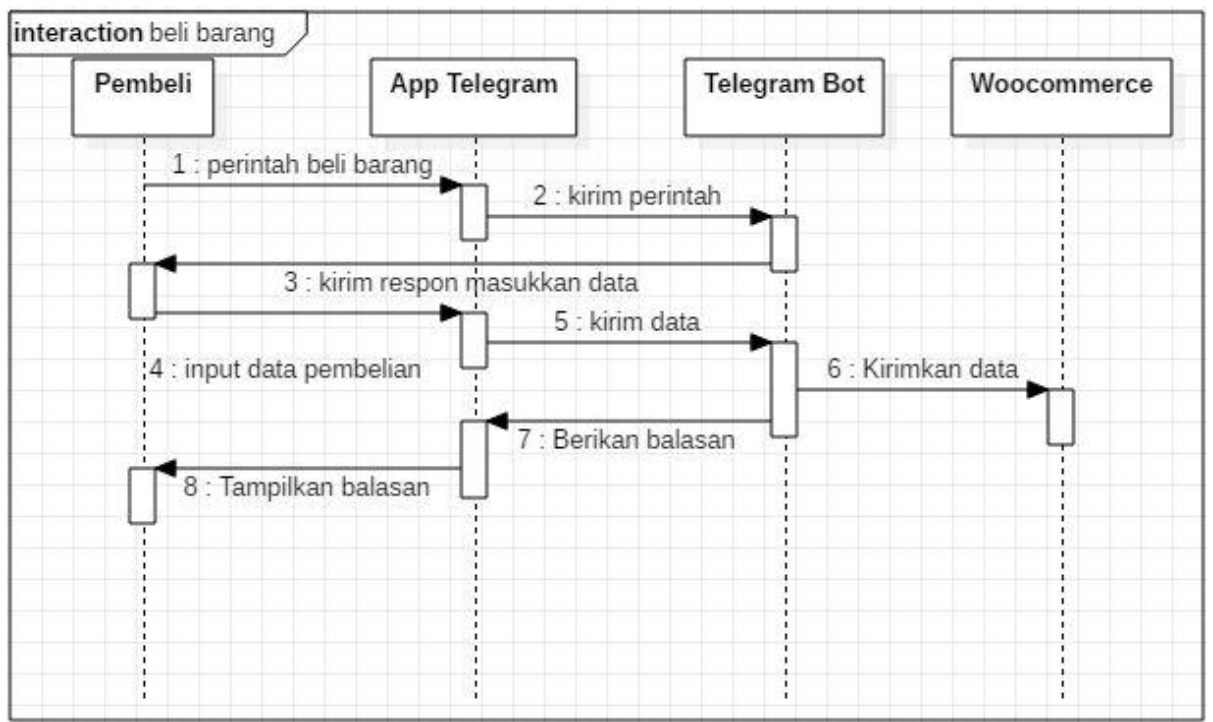

Gambar 4. Sequence Diagram Pembelian

REPOSITOR, Vol. 2, No. 6, Juni 2020: 717-726 
2.3 Perancangan Database

Pada penelitian ini phpMyAdmin digunakan sebagai aplikasi pengolah database. Sedangkan database dirancang dengan menggunakan database MySQL. Database digunakan untuk menyimpan data sementara saat pembeli melakukan pembelian. Terdapat tiga tabel yang akan digunakan oleh sistem. Tabel Tersebut adalah tabel cek_pesan, tabel order_product dan tabel customer. Desain tabel dapat dilihat pada Gambar 5.

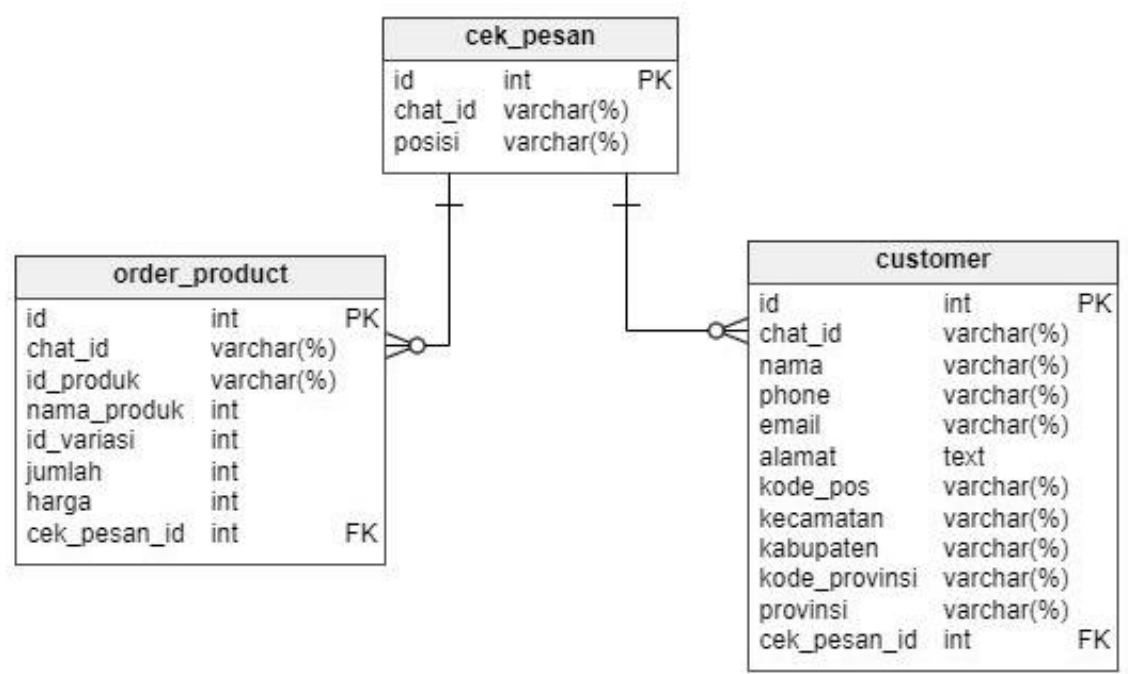

Gambar 5. CDM (Conceptual Data Model) yang Akan Dibangun Pada Sistem

\section{Hasil Penelitian dan Pembahasan}

Sistem Bot Telegram dibangun menggunakan bahasa pemrograman PHP dengan memanfaatkan framework Laravel. Metode yang digunakan untuk menjalankan Bot Telegram adalah metode Webhook dengan protokol https. Beberapa fungsi API Bot Telegram yang digunakan untuk mengirim pesan adalah sendMessage dan editMessageText. Sedangkan fungsi API Woocommerce yang digunakan adalah orders, products, product variations, product categories dan data.

\subsection{Tampilan Sistem}

Pada sub bab ini akan melihatkan beberapa contoh tampilan sistem Bot Telegram yang telah dibangun. Tampilan pada Gambar 6 menunjukkan tampilan awal. Untuk melihat tampilan ini pembeli harus memberikan perintah /start pada Bot.

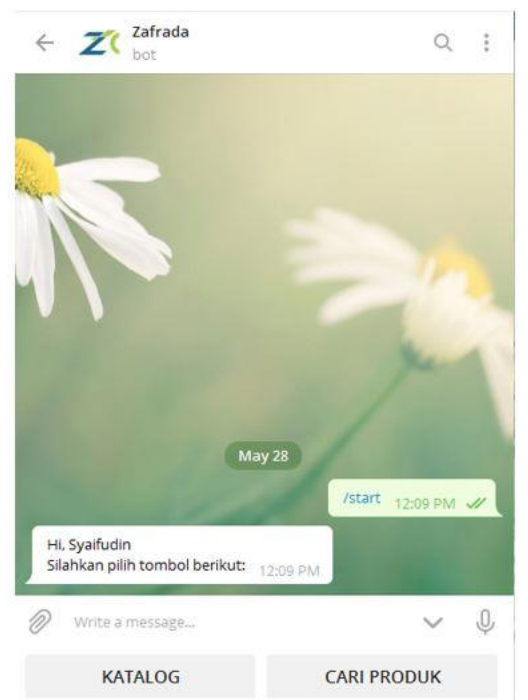

Gambar 6. Tampilan Awal Bot Telegram 
Tampilan selanjutnya adalah tampilan ketika pembeli memberikan perintah dengan menekan tombol Cari Produk atau tombol Katalog. Pada tampilan Cari Produk, pembeli dapat mengetikkan kata kunci atau nama produk yang ingin dilihat. Sedangkan pada Tampilan Katalog, pembeli sudah disediakan tombol pilihan katalog yang tersedia. Tampilan dapat dilihat pada Gambar 7.

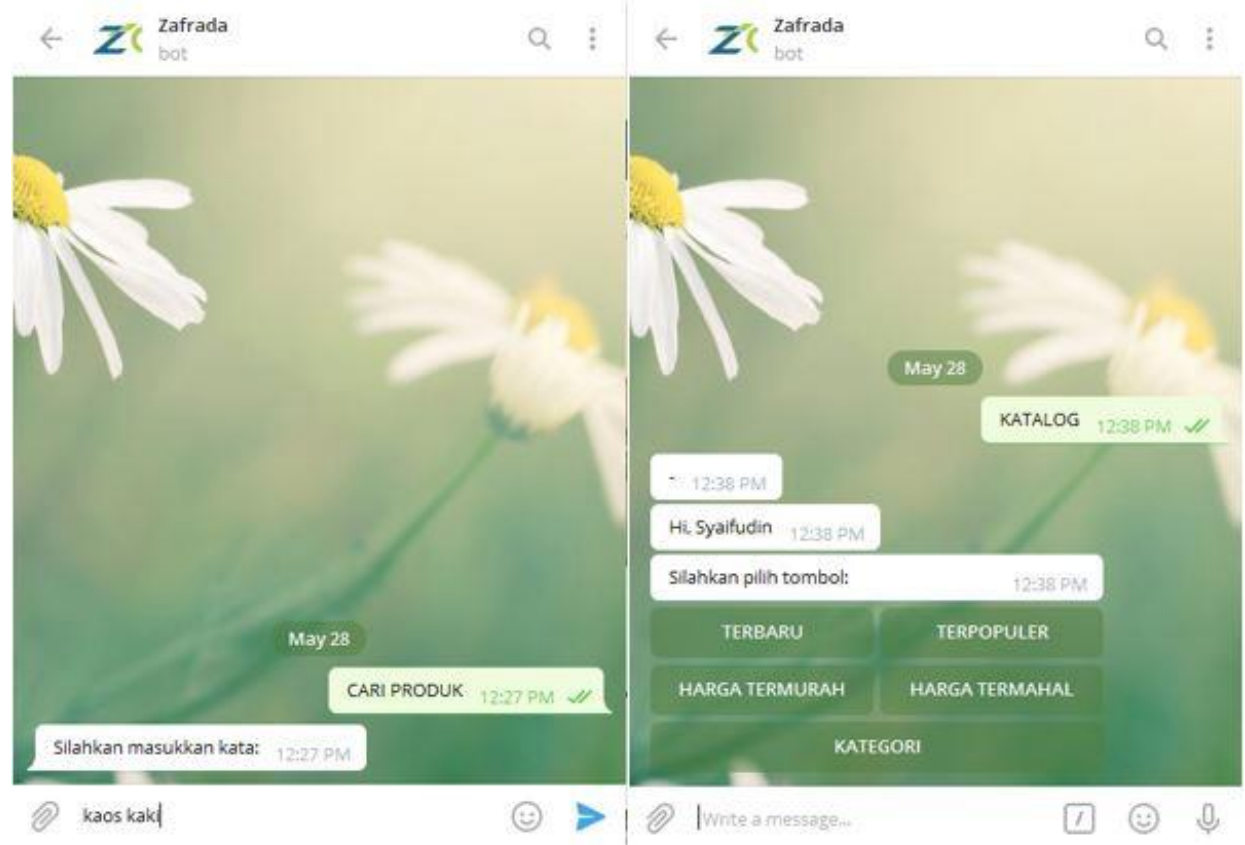

Gambar 7. Tampilan Menu Cari Produk dan Menu Katalog

Berikutnya adalah tampilan ketika pembeli menekan tombol kategori dan tombol halaman selanjutnya atau tombol halaman sebelumnya. Nama kategori langsung ditampilkan dalam tombol sehingga mempermudah pembeli untuk memilih kategori. Tampilan dapat dilihat pada Gambar 8.

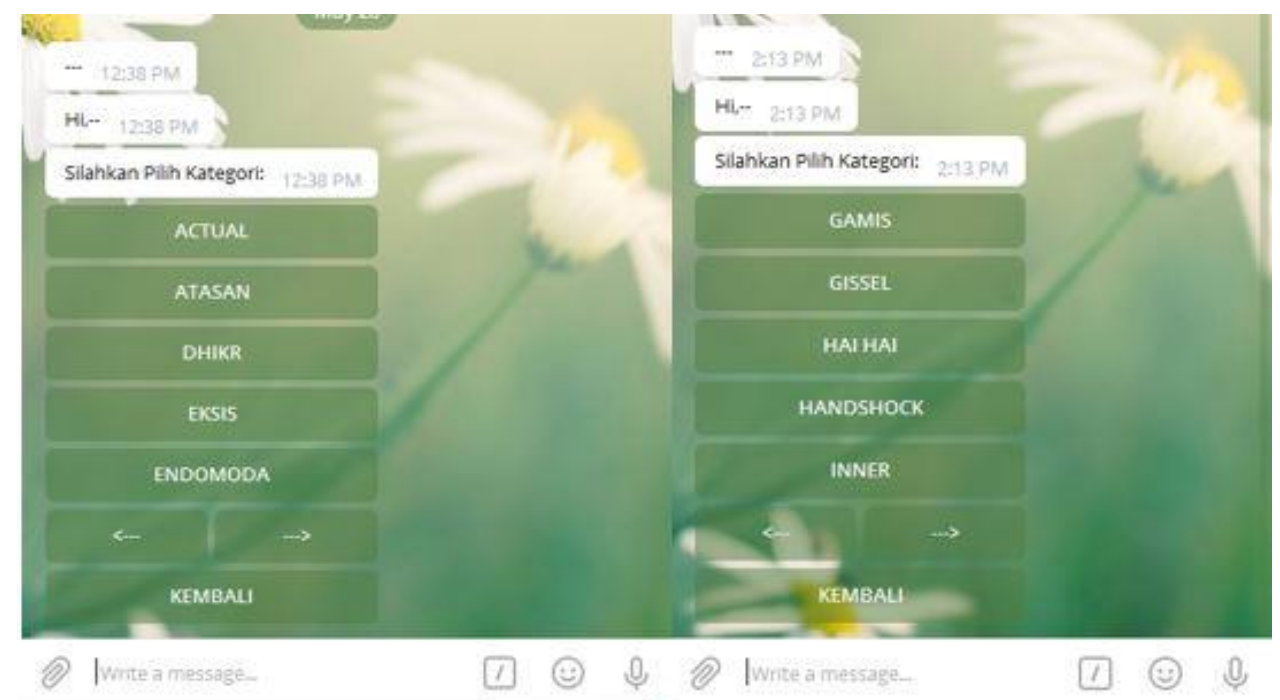

Gambar 8. Tampilan Menu Kategori dan Tombol Selanjutnya

Tampilan berikutnya adalah contoh tampilan Produk yang diambil dari data Woocommerce. Data yang ditampilkan adalah gambar, nama, harga reguler, ukuran, warna dan deskripsi produk. Tampilan dapat dilihat pada Gambar 9. 


\subsection{Pengujian Sistem}

Pada sub bab ini membahas mengenai pengujian yang dilakukan terhadap sistem Bot Telegram yang dibangun. Pengujian dilakukan untuk mengetahui apakah sistem Bot Telegram telah berjalan sesuai dengan yang diharapkan. Sistem Bot Telegram diuji dengan menggunakan pengujian blackbox atau pengujian fungsional sistem. Pengujian dilakukan kepada beberapa tampilan yang ada pada sistem. Rangkuman pengujian dapat dilihat pada Tabel 2 berikut.

Tabel 2. Rangkuman Pengujian Blackbox

\begin{tabular}{|c|c|c|c|}
\hline Tampilan yang Diuji & Inputan & $\begin{array}{l}\text { Contoh } \\
\text { Gambar }\end{array}$ & Kesimpulan \\
\hline Tampilan Utama & $\begin{array}{l}\text { Tekan tombol Cari Produk dan tombol } \\
\text { Katalog. }\end{array}$ & Gambar 6 & Berhasil \\
\hline Tampilan Cari Produk & $\begin{array}{l}\text { Memasukkan beberapa kata kunci } \\
\text { atau nama sebuah produk. }\end{array}$ & Gambar 7 & Berhasil \\
\hline Tampilan Katalog & $\begin{array}{l}\text { Tekan tombol Terbaru, Terpopuler, } \\
\text { Termurah, Termahal dan Kategori. }\end{array}$ & Gambar 7 & Berhasil \\
\hline Tampilan Kategori & $\begin{array}{c}\text { Tekan tombol nama kategori, halaman } \\
\text { selanjutnya, halaman sebelumnya dan } \\
\text { tombol kembali. }\end{array}$ & Gambar 8 & Berhasil \\
\hline Tampilan Produk & $\begin{array}{l}\text { Tekan tombol halaman selanjutnya, } \\
\text { halaman sebelumnya, tombol beli } \\
\text { barang dan tombol kembali. }\end{array}$ & Gambar 9 & Berhasil \\
\hline Tampilan Beli Barang & $\begin{array}{c}\text { Tekan tombol variasi produk, } \\
\text { masukkan jumlah produk, masukkan } \\
\text { data informasi pembeli dan tekan } \\
\text { tombol batalkan pembelian atau } \\
\text { tombol beli. }\end{array}$ & Gambar 10 & Berhasil \\
\hline
\end{tabular}

\section{Kesimpulan}

Berdasarkan hasil dari pembuatan Sistem Bot Telegram untuk otomatisasi transaksi toko online dapat disimpulkan bahwa:

1. Aplikasi Bot Telegram yang dapat berinteraksi dengan sistem Woocommerce telah berhasil dibuat.

2. Data dari sistem Woocommerce dapat diambil dan diolah oleh sistem Bot Telegram untuk kemudian ditampilkan di layar Aplikasi Telegram.

3. Aplikasi Bot Telegram dapat menampilkan data katalog dari sistem Woocommerce sesuai dengan kata kunci yang diberikan pengguna.

4. Aplikasi Bot Telegram dapat digunakan untuk melakukan pembelian produk dari sistem Woocommerce.

Sistem Bot Telegram yang telah dibuat masih memiliki banyak kekurangan. Untuk pengembangan sistem berikutnya, diberikan saran agar menghasilkan sistem yang lebih baik, di antaranya sebagai berikut:

1. Sistem dapat melakukan pembelian lebih dari satu barang dalam setiap transaksi.

2. Pemanfaatan Bot Payments API yang telah disediakan oleh Telegram agar sistem dapat menangani pembayaran.

3. Tambahkan fungsi atau modul baru untuk menangani beberapa exception atau error yang belum dibuat di sistem Bot Telegram.

\section{Referensi}

[1] Tim Publikasi Katadata, "Transaksi e-commerce," Katadata, 2016. [Daring]. Tersedia pada: https://databoks.katadata.co.id/datapublish/2016/11/16/transaksi-e-commerce-indonesianaik-500-dalam-5-tahun. [Diakses: 10-Mar-2018].

[2] H. Soeroso, A. Z. Arfianto, N. E. Mayangsari, dan M. Taali, "Penggunaan Bot Telegram Seagai Announcement System Pada Intansi Pendidikan," Semin. MASTER 2017 PPNS, vol. 2, no. 1, hal. 45-48, 2017.

[3] Alexander Haryanto, "Menilik Pengguna Messenger di Indonesia," tirto.id, 2016. [Daring]. Tersedia pada: https://tirto.id/menilik-pengguna-messenger-di-indonesia-ccjz. [Diakses: 10Mar-2018].

REPOSITOR, Vol. 2, No. 6, Juni 2020: 717-726 
[4] D. Utomo, M. Sholeh, dan A. Avorizano, "Membangun Sistem Mobile Monitoring Keamanan Web Aplikasi Menggunakan Suricata dan Bot Telegram Channel," Semin. Nas. Teknoka, vol. 2, no. 2502, hal. 1-7, 2017.

[5] R. J. Putra, N. P. Sastra, dan D. M. Wiharta, "Pengembangan Komunikasi Multikanal Untuk Monitoring Infrastruktur Jaringan Berbasis Bot Telegram," vol. 5, no. 2, hal. 152-157, 2018.

[6] G. Sastrawangsa, "Pemanfaatan Telegram Bot Untuk Automatisasi Layanan Dan Informasi Mahasiswa Dalam Konsep Smart Campus," Konf. Nas. Sist. Inform., hal. 772-776, 2017.

[7] Telegram, "Telegram Bot," Telegram.org. [Daring]. Tersedia pada: https://core.telegram.org/bots. [Diakses: 10-Jun-2019].

[8] R. Dewi Risanty dan A. Sopiyan, "Pembuatan Aplikasi Kuesioner Evaluasi Belajar Mengajar Menggunakan Bot Telegram Pada Fakultas Teknik Universitas Muhammadiyah Jakarta (FTUMJ) Dengan Metode Polling," Univ. Muhammadiya Jakarta, vol. 4, no. 45, hal. 1-9, 2017.

[9] A. Cokrojoyo, J. Andjarwirawan, dan A. Noertjahyana, "Pembuatan Bot Telegram Untuk Mengambil Informasi dan Jadwal Film Menggunakan PHP," J. Infra, vol. 5, no. 1, hal. 224227, 2017.

[10] O. Leavy, "Aplikasi Bot Telegram Untuk Media Informasi Perkuliahan Program Studi Informatika-Sistem Informasi Bisnis Universitas Kristen Petra," Nat. Rev. Immunol., vol. 7, no. 12, hal. 921-921, 2007. 